Article

\title{
Systems Analysis to Promote Frames and Mental Models for Sustainable Water Management
}

\author{
Peder Hjorth $^{1, *}$, Kaveh Madani ${ }^{2}$ \\ ${ }^{1}$ Department of Water Resources Engineering, Lund University, Lund, Sweden \\ ${ }^{2}$ Department of Civil, Environmental and Construction Engineering, University of Central Florida, \\ Orlando, FL 32816, U.S.A \\ E-Mails: , Peder.Hjorth@tvrl.lth.se; Kaveh.Madani@ucf.edu
}

Received: 16 September 2013 / Accepted: 31 October 2013 / Published: 01 November 2013

\begin{abstract}
In the water sector, there have been numerous failures in projects aiming at sustainable development and there have been some, but less numerous, examples of successes. However, the most striking observation is the near universal failure to learn from these examples. Somehow, scientists and decision makers have allowed the indications of new approaches and opportunities go undetected because they did not fit with their mindsets or perceptual apparatus. This paper discusses some of the mental frames that have hampered the progress towards sustainable development. It analyzes where these frames come from, who is promoting or defending them, and what can be done to change these frames in ways that are more in line with the basic tenets of sustainable development. It is found that there is a lack of consistency in the interpretation of sustainable development. Most sustainability initiatives have failed because the environment and development were never properly brought together. The "environment" is where we live: and "development" is what we all do in attempting to improve our lot within that abode. The two are unseparable (Our Common Future). Thus, there is a need to draw on diverse disciplinary perspectives and to cut across sectoral boundaries to counter the monovalent approaches that have dominated mainstream enquiry and practice. To that end, systems analysis can help produce enabling frameworks for process changes. These frameworks should define general objectives and means of verification of progress without specifying uniform approaches and activities. Systems analysis is also a methodology helping to make sure that problems posed are adequately defined and that helps detecting biases in goal formulation stemming either from dominant actors or from "solution oriented approaches".
\end{abstract}


Keywords: Sustainable water management; mental models; frames; integration; coordination; learning; systems analysis.

\section{Introduction}

As pointed out in UN's Agenda 21, water is one of our most important resources but, at the same time, a severely mismanaged resource. Agenda 21, therefore, urges all nations to restructure their management systems to allow for a more comprehensive consideration of the principles of integration, coordination, and consultation, respectively. It is only by mobilizing social, economic and environmental actions together that we can make real progress and hope to inspire people to believe that a better world is within its reach and to act accordingly.

We have experienced numerous failures in sustainable development projects. The problem is not the lack of sustainability initiatives. Instead, the major problem is that we have failed to learn from our failures. We work hard, but separately, to solve interlinked problems. Our separate actions have resulted in our failure in bringing environment and development together properly. People were working hard - but often separately - on interlinked problems. However, the most striking observation is the near universal failure to learn from these examples. Somehow, scientists and managers have allowed the sounds of new and opportunity go undetected because they did not fit with their mindsets or perceptual apparatus. Lackoff [1] gives a clue to why it is difficult to learn from experience - we typically think in terms of unconscious structures, called "frames", that are physically realized in neural circuits in the brain. All our knowledge makes use of frames and our thinking and talking involve "framing". Thus, observations that do not fit into our frames are disregarded. We cannot avoid framing, and repetition makes the frames stronger. Then, one wonders whose frames are being activated and thus strengthened in the brains of scientists, managers, and journalists when it comes to sustainable development.

Unfortunately, there is a lack of consistency in the interpretation of sustainable development and a confusion in terms, perceptions, and concepts [2], leading to the failure of our brains in developing strong and unique "sustainability frames". Thus, there is a need to clarify the semantics and to identify the major weaknesses in current concepts and reasoning - weaknesses that need to be addressed if sustainable development is to be a meaningful paradigm for development rather than a meaningless cliché. In addition, development is a process of directed change whose definition must include both the process goals and the means to achieve these. However, the debate has been heavily burdened by a helter-skelter mixing of fundamental objectives and operational means. [3]. Also, as time goes by and experience accumulates, we often understand, expect, and invest in our system as it was, rather than as it might become. A conservative bias is built in and gives us confidence in our old system [4]. Therefore, we increasingly face situations where our assumptions about how the world works are invalid or suboptimal. Still, however, our tools and procedures build on these assumptions and an idea that experience from past operations holds true [5].

The water resources community in particular seems to suffer from a collective or institutional complacency in tackling the sustainable development problem [2]. The main reasoning tends to be that we have developed a very sophisticated range of systems models, and there is no reason to change 
them, even if they suffer from some shortcomings making them inappropriate for sustainability monitoring and assessment. So, any concern or criticism expressed about their utility is essentially dismissed as "spin". Consequently, there is reason to voice serious concern about the questions water professionals ask and the answers they provide concerning sustainable development and water resources sustainability [2]. The water world is mainly dominated by normative policies prescribing what "good development" is all about. As new buzzwords, or amoeba words, continue to be invented or reinvented, policies continue to maintain their shiny images of how water resources or water supply should be managed. The water sector is still rife with supply-driven interventions spurred by development missionaries promoting standard approaches and policy-makers and water experts are often skeptical towards research insights that challenge the collective wisdom of policies [6]. Decisionmakers are just people, and people make mistakes. However, they should not go on committing the same mistakes repeatedly. Therefore, there is a need to devise institutions whereby fallible and imperfect administrators may be helped to learn from past mistakes if sustainability is ever wanted to be achieved.

This paper addresses the nature and extent of the problematic gap between the dominant theories and current realities and suggests some means for breaking down these dichotomies. It discusses some of the problems that have hampered the progress towards sustainable water management and argues that we badly need to change current frames and mental models in ways that are more in line with the basic tenets of sustainable development. We assert that we are up against a set of new challenges that are going to demand new thinking and solutions that we might not have started to think seriously about yet. It is suggested that systems analysis is a powerful instrument for finding out what is wrong with "business as usual" and for identifying suitable strategies for coping with the menacing and uncertain future that we seem to be facing.

\section{Some Problematic Frames}

\subsection{Market-driven Science and Development}

To be able to address the challenges of sustainable development, there is a need to closely examine the current culture and modes of operation [7]. To a certain extent, modern science and technology seems to be a market-driven enterprise dominated by excessive technological optimism. If progress is to occur, this issue must, at a minimum, be openly and respectfully debated within scientific and engineering communities. Science has had a tendency to be deeply enmeshed in social, economic, and political relationships with the corporate state. Consequently, major scientific effort has been directed towards improving production technology to enlarge surplus at the expense of sustainability impacts. Furthermore, there is still considerable pressure from financial institutions, big business, and some world leaders to ensure that the development agenda remains on economic growth. Equating development with economic development obscures the concerns for human development, equity, and social justice.

\subsection{Truth, Emotions, and Objectivity}

Another important frame can be traced to the Enlightenment idea about our thinking, claiming that reason is conscious, unemotional, logical, and abstract. This has been shown to be false. In real life, there is no objective truth as emotions and values significantly impact our thinking. But still the 
Enlightenment idea is the dominant perception within science. Thus, if ends and goals are required, the optimistic technician will find them in a finality which can be imposed on technical evolution precisely because this finality can be technically established and calculated. It seems clear that there must be some common measure between the means and the ends subordinated to it. The required solution, then, must be a technical inquiry into ends, and this alone can bring about a systematization of ends and means. The problem reduces to a technical one; to establish numerically and mechanistically, the constancy of individual and social requirements [8].

\subsection{Protecting Existing Mental Models}

Water resources scientists and engineers have a tendency to preoccupy themselves with issues close to their comfort zones such as flow forecasting, groundwater development, dam design, or operation and maintenance of equipment. Based on this tendency they may try to get by through cultivating skills that can superficially "cover" their confusion or ignorance and help conserving their mental frames. A frame modification would imply adjustment, insecurity, and even confusion, possibly not just for the individual but for an entire community. Thus, to rely on what you know means that you dodge the problems and rely on a survival technique that temporarily rewards you for selfishly bringing old, possibly unsuccessful work habits into a new situation [8].

The mental models of mainstream science are simply not fit to deal with issues like nonstationarity, uncertainty, and values. The discussions about the climate change possibility have made it quite clear that we live in an evolving and unpredictable environment. Still, as Simon [9] observed, we drown in detailed statistical and predictive reports, but lack the elementary analytical and planning capabilities needed for sensible system design; capabilities we know perfectly well how to create. Nor can real life science be objective. This was observed already by Thoreau [10], who claimed that: "In our science and philosophy, even, there is commonly no true and absolute account of things. The spirit of sect and bigotry has planted its hoof amid the stars." Churchman [11], an early and very important champion of the systems approach, observed that we must not merely show a man how to better gain his goals but also estimate for him what his goals really are - something he may not be aware of at all. Such estimation would call into question the objectivity and impartiality of the scientist.

It has become increasingly clear that knowledge, both scientific and lay, is incomplete and varies among individuals. This gives rise to uncertainties about how to deal with the risks and hazards that are invisible from partial perspectives. Uncertainty affects nearly every domain and particularly in the case of water, there is only incomplete and imperfect information to guide our management choices. Water and the coupled natural-human system in which we manage it are, in most cases, extremely complex. A multitude of often poorly understood feedbacks, and significant time lags result in a system that is almost certain to produce unexpected results [12].

\subsection{Materialistic Mental Frames}

Another frame, hampering our move toward sustainability, is related to the scientist's view being essentially material - how many parts of this or that do we need or can we tolerate? However, sustainable development is very much about values and emotions. Therefore, we need to talk at the level of values and frame issues in terms of moral values rather than to present laundry lists of actions to be done and index values to be met. However, the social science component of sustainability efforts is especially challenging for traditionally trained natural science experts, who are frequently frustrated 
by issues such as public perception and the role of politics in science [13]. They seem to be sometimes out of touch with the "real world". Thus, the more research is grounded in "down to earth" realities, the greater the credibility of scientists - and in the best situations, such an approach may trigger society to improve its adaptive capacity and become more nimble at management that can adapt to rapidly changing social and environmental conditions [13].

\subsection{Community Driven Mental Convergence}

Within the profession, mental models tend to converge over time. Professionals read the same journals, go to the same conferences, and speak to the same consultants. As the years pass, the intellectual pool might become a stagnant pond. Successful management feats might then spawn best practices and be translated into operational policies, which harden into fossilized strategies. Many water managers worry over the great number of potential problems, while they ought rather to worry over the scarcity of effective remedies and most importantly the lack of preventive measures. Such strategy decay is like cancer; it happens little by little, and the longer you wait to deal with it, the more deadly and costly it becomes [14].

\subsection{Management Inertia}

In many organizations, considerable effort is made to conceal mistakes even from those who make them - mistakes are considered to be a no-no [15]. We are much too satisfied with how things are, and we think the time required to make needed transformation exceeds the time we have, so we leave it for the next generation. The deeper we get into the consequences of the direction we are currently taking, the more difficult it will be to make the transition.

There is no scarcity of opportunities for change. As Wayne Dyer says: "There is only a scarcity of resolve to make it happen." As Hamel [14] put it: "We are just not discontented enough with how much our organizations really suck and we haven't been very ambitious in trying to make them different". Too many managers are satisfied with the way things are and are going. They are afraid that any intervention is likely to cause problems and be costly. Thus, they try to "ride the tide" without "rocking the boat". They take a position on an issue only when forced to; "forced to" meaning that it is the only way to prevent change from happening. Whenever possible, they use words instead of actions. They are prolific producers of policy statements, white papers, strategy documents, position papers, reports, memoranda and any other kind of documents that can substitute for action [16]. If forced to act, they tend to opt for panaceas like total quality management, core competence, benchmarking etc. However, panaceas rarely work. Instead of trying to rethink why a panaceas failed and learning from that, they simply look for the next panacea. The reason why panaceas fail is quite simple - panaceas are anti-systemic.

\section{Systems Analysis for Tackling the Management Problems}

Most things that have turned into conventional wisdom are almost by definition wrong, or at least overstated [17]. Therefore, we need to identify and challenge intellectual consensuses that have gone beyond what theory and experience can support. Whenever a convergent belief is identified, one needs to ask if it rests on some inviolable law of physics or is simply an artifact of our devotion to precedent. Hereby, it can be helpful to think in conditional terms: different remedies are required by different 
constraints. This way of thinking leads to a contextual type of approach that is diagnostic rather than a blueprint or kitchen-sink one.

The German philosopher Kant once said that common sense unites while science divides. Thus, if we want a unified, common effort, we have to work within a common sense framework. Systems analysis can provide such a framework. Systems analysis is not a method in itself. It is more a way to relate to knowledge, a way to relate to parts within an integrated whole, where the whole system is more important than the parts. It is also a methodology trying to make sure that the problems posed are adequately defined. System performance is evaluated relative to desired system goals, and procedures are there to detect biases in goal formulation stemming either from dominant actors or from "solution oriented approaches".

The emphasis should be on determining conditions for welfare improvements rather than on searching for maximum values, on avoiding dead-end streets rather than on computing the shortest distance, and on adaptability rather than optimum adjustment. The major concerns should be about systemic fit and self-cultivation. In some cases revelations may work to change a person's frames or worldview in one go. However, in most cases, it is a matter of a step-by-step continuous process. In order to be digested, new information must make sense relative to existing frames. Therefore, the first piece of information must pave the way for digestion of the second, and so on.

Systems thinking is helpful in this respect. According to Churchman [18], systems have a number of essential properties. They inter alia have a decision-maker, a purpose, beneficiaries, and an outer environment with which it interacts. It consists of parts, where the crucial issue is how well the parts fit and work together, not the performance of an individual part. These properties can be used to create an easy to understand checklist:

- Who is the decision-maker, i.e. who is responsible for the system's impact on people, environment, and the society?

- What is the purpose of the system? How was that chosen?

- Who are the beneficiaries? How and why have they been chosen?

- Does the system function in a harmonious way with its outer environment?

- Do the parts fit together and work properly?

If people get together and scrutinize these issues, it is quite likely that some serious questions will emerge and make the participants more open to new perspectives. Participation is a much used word overused in fact - and underemployed as a concept. Yet, it can be the key to major improvements at all levels of the development process [19]. There has been a tendency to neglect the many everyday contexts within which institutions and problems are located and their rootedness in local history. Agencies must, thus, not be the source from which all the opinions, all the routes, all the answers, and all the truth emanate. Instead, they should move forward by learning from other agents in their environment.

\section{Future Challenges}

Sustainability is not so much about efforts to preserve beautiful vistas or cute koala bears as it is the science of ensuring that species can persist [20]. We are now realizing that human activity is 
consuming natural resources and ecosystem services at a much higher rate than that at which they can be replenished or restored. This is producing a sobering recognition that our current ways of doing business are unsustainable. It is a major challenge, but also an exciting opportunity, for scientists and engineers to harness their knowledge and creative capacity to contribute to the goals of environmental stewardship and sustainable development [8]. In some circles, though rarely water ones, sustainable development is becoming a scientific and technological endeavor that seeks to enhance the contribution of knowledge and to deepen our understanding of socio-ecological systems while exploring innovative mechanisms for producing knowledge that is relevant, credible, and legitimate to local decision-makers.

The primary aim of planning is not to produce forecasts and prepare for the future on their basis, but to act energetically in order to achieve a desired future. As Saint-Exupery [21] expressed it: "The future is not to be predicted but to be enabled". Systems analysis can be helpful in this respect because it is an interactive planning method that eliminates the need for forecasts and puts assumptions and contingency planning in its place. An assumption is not a prediction. For example, we do not carry a spare tire in our cars because we predict we will have a flat tire on our next trip. In fact, most of us predict we will not. We carry a spare tire because we assume that a flat tire is possible [15].

There are some fundamental properties of systems: First, a system's performance derives from the interaction of its parts, not from the actions of its parts taken separately. If we disassemble an automobile - even though we have all the parts in one place - we do not have an automobile because the automobile is the interaction of the parts - not the sum of them [15]. By the same token, an all-star soccer team is not necessarily as good as the best team in the pool of teams that the players were drawn from. Secondly, in most cases, problems are not best treated where they appear. For instance, if you get a headache, you do not do brain surgery. You swallow a pill because a pill in your stomach will eventually act on the pain in your head. Knowledge of interactions allows you to enter the system at the most effective point. This fact has tremendous implications. Thirdly, systems thinking has taught us that, in reality, we have systems of problems and we have to act on the whole set. Although solving each of the problems separately could improve the parts, it could very well destroy the whole. Finally, systems thinking points to the importance of control, i.e. receiving feedback on the outcome of what a system does, determining its deviation from expectations, continuously diagnosing mistakes and errors, and prescribing corrective actions [15]. We know that no matter how well we plan, we are going to be wrong and make mistakes. Feedback controls, however, help us detect our mistakes and correct and learn from them.

To counter the proliferation of simplistic interventions for water management, we need interventions that have a processual, i.e. a systematic series of actions directed to some end, rather than a product-oriented character [22]. By privileging a particular source of knowledge - in most cases conventional science - national and global policies and regulatory frameworks act to mask knowledge uncertainties and to exclude alternative perspectives and perceptions. This points to the need not only for inclusionary, participatory decision-making processes, but also for approaches to institutional learning that reflects on, and makes best use of, the plurality of perspectives available. Through such framing, alternative perspectives on the environment that go beyond static notions of equilibrium and balance, and incorporate (rather than eliminate) uncertainties, may become more central [22]. Therefore, it is encouraging that disciplines are increasingly thought of as points of view, most of which are applicable to the study of most phenomena and problems. For instance, no discipline is 
irrelevant in efforts to solve ecological problems [16]. In mechanistic thinking, behavior is explained by identifying what caused it, never by its effect. In systems thinking, behavior can be explained either by what produced it or by what it produces, or is intended to produce. Study of the functions, goals, and purposes of individuals and groups - even machines - has yielded a greater ability to evaluate and improve their performance [16].

A system is a set of two or more interrelated elements of any kind; for example concepts (as in mathematics), objects (as in the human body), or people (as in social systems). Therefore, it is not an ultimate indivisible element but a whole that can be divided into parts. A system is more than its parts. A human being, for example, can do things that none of its parts can (such as writing or running). A system's performance depends critically on how well the parts fit and work together. It also depends on how the system relates to its environment - the larger system of which it is a part - and to the other systems in that environment. The Systems Age is more interested in putting things together than to break them down into parts. Neither way of thinking negates the other, but by synthetic thinking we can gain understanding of individual and collective human behavior that cannot be obtained by analysis alone [16].

With systems thinking, you are quite likely to become aware and discontent with the current state of affairs or the way they are going. This creates some new frames in your brain. You then want to design a desirable future and also bring it about. You feel that we are capable of controlling a significant part of the future as well as its effects on us. You try to prevent, not just prepare for threats and to create not merely exploit opportunities. Ideally, you should pursue ideals (such as impeccable sustainable development) that you know can never be attained but that can be continuously approached. Thus, you try neither to resist, ride with, or ride ahead of the tide; you try to redirect it.

The creation of a vision or idealized future for a public or private system often brings some interesting results; it can lead those involved in it to become conscious of self-imposed constraints and hence make it easier to remove them. It also forces examination of externally imposed constraints, which are usually accepted passively. Ways of removing or "getting around" such constraints are then explored, often with success as ideas or plans, that seem not to be feasible when considered separately, may be found to be either feasible, or nearly so, when considered as components of a whole [16].

\section{Conclusions}

Sustainable water management is unachievable at the rate of "improvement" we are currently making by means of incremental and fragmented efficiency. We are unlikely to make the changes needed quickly enough unless we start transforming our dominant paradigms. We need a framing and understanding of living systems and their interrelationships in an integrated way - a whole systems mental model. We need something that helps us understand the dynamics and interactions at work in a water resources system - a framework that focuses not so much on logical arguments or empirical verifications but on its effects on the sense-making and empowerment of those who use it [23].

We isolate, bifurcate, and package complex issues into those that can be analyzed by reduction, and discard those which belong to categories that cannot be easily quantified or characterized by a number. This has taken us to a state where we know a lot but understand very little, but we are, hopefully, beginning to understand that knowledge without understanding or understanding without knowledge is incomplete. We therefore need to undertake, at last, the navigation we have so far 
postponed [24]. Changing our current mental model is the only way we can achieve a permanent and evolving change - what is required for "sustaining sustainability" as a development model.

The needed change of frames requires a conscious act of choice that begins with becoming aware of the way current mental models color what we see as real, and how we think of ourselves and our world. Such a change might not be easy, but it is perfectly doable. Meadows [25] claimed that using calculation is the slowest way to change a system. There is not much power in numbers. The fastest way is to change the mental model or paradigm out of which the system arises. However, individuals and societies do resist challenges to their paradigms harder than they resist any other kind of change.

Still, new challenges require new thinking and changed priorities. Therefore, we need to update our sense of what is important and allow systems thinking to help us come to grips with mistaken beliefs. That would, most likely, foster an understanding that if sustainable development is to evolve and be sustained, we need to resort to increasingly flexible and diverse approaches in the development of strategies for a society living in harmony with itself and the environment.

\section{Conflict of Interest}

"The authors declare no conflict of interest".

\section{References and Notes}

1. Lakoff, G. "Why it Matters How We Frame the Environment" Environmental Communication: A Journal of Nature and Culture, Vol.4, No.1, pp.70-81, 2010

2. Hjorth, P.; Madani K. "Sustainability Monitoring and Assessment: New Challenges Require New Thinking" Journal of Water Resources Planning and Management, forthcoming.

3. Lélé, S. M. "Sustainable Development: A Critical Review.” World Development, 16(6), 607-621. Prentice-Hall, 1991.

4. Douglas, M. Purity and Danger: An Analysis of Concepts of Pollution and Taboo. Routledge and Keegan Paul PLC, First Edition (June 1966).

5. Guijt, I. "Seeking Surprise - Rethinking monitoring for collective learning in rural resource management." Dissertation, Wageningen University, Wageningen, 2008.

6. Mörck-Jensen, K. "Viewpoint - Swimming against the current: Questioning development policy and practice" Water Alternatives Vol. 6, No. 2, pp. 276-283, 2013.

7. Ad Hoc Advisory Group to the Consortium on Science and Technology for Sustainable Development. "Harnessing Science, Technology and Innovation for Sustainable Development." A report to the International Council for Science (ICSU) - Initiative on Science and Technology for Sustainability (ISTS) - TWAS, the Academy of Sciences for the Developing World, 2005.

8. Ellul, J. The Technological Society. New York: Knopf, 1964

9. Simon, H. “Administrative Decision Making” IEEE Engineering Management Review Vol. 1, Issue 1, pp. 60-66, 1973.

10. Thoreau, D. H. "Life Without Principle" The Atlantic Monthly, 1863

11. Churchman, C. W. Prediction and Optimal Decision: Philosophical Issues of a Science of Values Englewood Cliffs: Prentice-Hall, 1961.

12. Mirchi A., Madani K.; Watkins D.; Ahmad S. "Synthesis of System Dynamics Tools for Holistic Conceptualization of Water Resources Problems", Water Resources Management, 26 (9), pp. 2421-2442. 
13. Jacobs, K.; Garfin, G.; M. Lenart "More than just talk: Connecting science and decisionmaking" Environment Vol 47, No. 9, pp. 6-21, 2005.

14. Hamel, G. What Matters Now Jossey-Bass, San Francisco, CA, 2012.

15. Ackoff, R.L. "Strategy, Systems, and Organizations: An Interview with Russell L. Ackoff". Strategy and Leadership March/April, 1997.

16. Ackoff, R.L. Redesigning the Future New York/London, Wiley, 1974.

17. Rodrik,D. "What is wrong (and right) in economics?" 2013 http://rodrik.typepad.com/dani_rodriks_weblog/2013/05/what-is-wrong-and-right-ineconomics.html Accessed 2013-09-20

18. Churchman, C. W. The Design of Inquiring Systems: Basic Concepts of Systems and Organization New York/London, Basic Books, 1971.

19. Catley-Carlson, M. "On Common Ground?" Message to the global Health Council. Posted 16 May 2003. www.globalhealth.org/reports/report.php3?id=92

20. Hilger, H. "The Definition of Sustainability” EWRI Currents Vol. 11, No. 1, Winter 2009.

21. de Saint-Exupery, A. Citadelle (translated into English as The Wisdom of the Sands) Gallimard, France, 1948

22. Mehta L., Leach, M., Newell, P., Scoones, I., Sivaramakrishnan, K. \& Way, S-A. Exploring Understandings of Institutions and Uncertainty: New Directions in Natural Resources management. IDS Discussion Paper 372. Institute of Development Studies, University of Sussex, Brighton, 1999.

23. Kurtz, F., and Snowden., D. "The New Dynamics of Strategy - sense-making in a complexcomplicated world." IBM Systems Journal, 2003.

24. Max- Neef, M. A. "What Next? From Knowledge to Understanding: Navigations and Returns". Draft thematic paper. Dag Hammarskjöld Foundation, no date.

25. Meadows, D. H. "Places to Intervene in a System" Whole Earth Winter, 1997.

(C) 2013 by the authors; licensee MDPI, Basel, Switzerland. This article is an open access article distributed under the terms and conditions of the Creative Commons Attribution license (http://creativecommons.org/licenses/by/3.0/). 